\title{
Clinical effect of three important cytokines on the pathogenesis of equine herpes virus 9 (EHV-9), equine herpes virus 1 (EHV-1) and Zebra borne EHV-1
}

\author{
Asmaa G. Saleh ${ }^{1,2}$,Osama M. Abas ${ }^{3,4}$, Nasr M.Y. ${ }^{2}$, Noha A. Beder ${ }^{2}$, Nabil M. \\ Bakeer ${ }^{2}$,Nagwan El-Habashi ${ }^{1,5}$,Tokuma Yanai ${ }^{1}$ \\ ${ }^{1}$ Laboratory Of Veterinary Pathology, Faculty Of Applied Biological Sciences, Gifu University, 1-1 Yanagido, \\ Gifu, 501-1193, Japan. \\ ${ }^{2}$ Department Of Animal Medicine, Faculty Of Veterinary Medicine, Damanhour University, El-Beheira, Egypt. \\ ${ }^{3}$ Laboratory Of Veterinary Microbiology, Faculty Of Applied Biological Sciences, Gifu University, 1-1 \\ Yanagido, Gifu, 501-1193, Japan. \\ ${ }^{4}$ Department Of Animal Medicine, Faculty Of Veterinary Medicine, Alexandria University, Alexandria, Egypt. \\ ${ }^{5}$ Department Of Veterinary Pathology, Faculty Of Veterinary Medicine, Kafr El-Sheikh University, Kafr El- \\ Sheikh, Egypt.
}

\begin{abstract}
This study aimed to investigate and compare the clinical roles of three important cytokines Tumor necrosis factor - $\alpha(T N F-\alpha)$, Interferon-y (IFN-y) and Interleukine-6 (IL-6) in the pathogenesis of EHV-9, EHV-1 and Zebra borne EHV-1. Eighty four male Syrian hamsters were used in this study, divided into four groups, each group included twenty one animals, The $1^{\text {st }}$ group served as the control group and received $50 \mu l$ of MEM- $\alpha$ medium by intranasal administration. The $2^{\text {nd }}, 3^{\text {rd }}$, and $4^{\text {th }}$ group received $50 \mu l$ of a solution containing $1 \times 10^{4}$ PFU of EHV-9, EHV-1, and Zebra borne EHV-1 respectively by intranasal route. Hamsters were observed for clinical signs and body weight gain three times daily for 7 DPI, three hamsters from each group were used for collection of blood samples at1, 2, 3, 4, 5, 6 and 7 days post infection (DPI). EHV-9 infected group showed clinical signs earlier and were more severe and progressive than both EHV-1 and Zebra borne EHV-1 infected group. Serum TNF- $\alpha$ level was significantly increased in EHV-9 infected group compared to both other two infected groups at both $3^{\text {rd }}$ and $5^{\text {th }}$ DPI, both EHV-1 and Zebra borne EHV-linfected groups showed decrease in serum TNF- $\alpha$ level at $6^{\text {th }}$ and $7^{\text {th }}$ DPI compared to $5^{\text {th }}$ DPI. In addition to, serum TNF- $\alpha$ level was significantly increased in EHV-9 infected group compared to both EHV-1 and Zebra borne EHVlinfected group at $3^{\text {rd }}$ and $4^{\text {th }}$ DPI. However, Zebra borne EHV-linfected group showed a significantly lower serum IFN-y level compared to both EHV-9 and EHV-1 infected group at $4^{\text {th }}$ and $5^{\text {th }}$ DPI. Also, serum IL-6 level was significantly increased in EHV-9 infected group compared to both EHV-1 and Zebra borne EHV-1infected group at $4^{\text {th }}$ DPI and significantly increased in EHV-9 infected group compared to Zebra borne EHV-linfected group at $5^{\text {th }}$ DPI.
\end{abstract}

Keywords: Cytokines, EHV-1, EHV-9, Zebra borne EHV-1, Pathogesis.

\section{Introduction}

Equine herpesvirus-1 (EHV-1) is a critical equine viral pathogen that induces its real effect by initiating premature birth storms or sporadic premature births in pregnant mares, early neonatal deaths in foals, respiratory disease in foals and myeloencephalopathy[1]. EHV-9 is a new member of the equine herpes viruses. It was isolated for the first time from Thomson's gazelles (Gazella thomsonii) that died of fulminant encephalitis in a Japanese zoo $[2,3]$. Gazelle was not considered a natural host of the isolated herpes virus, the reservoir of the virus is still unknown[4].

GHV-1 was serologically closely related to EHV-1 and EHV-4[2]. However, DNA fingerprints of GHV-1 with BamHI, BgIII, and EcoRI were different from those of EHV-1 and other EHVs. DNA identity of GHV-1 was estimated to be about $95 \%$ to EHV-1 and EHV-8, and $60 \%$ to EHV-4, based on nucleotide sequences of the glycoprotein $\mathrm{G}$ gene and a conserved region of the glycoprotein B gene. Therefore GHV-1 has been established as a new equine herpes virus, (EHV-9)[4]. A new strain of EHV-1 was isolated from zebra. This strain, named "zebra-borne EHV-1", was also isolated from an onager and a gazelle in U.S.A from azoological gardens. The complete sequences of the genome of the 3 strains were determined. 99\% identities was shared with each other, while they shared $98 \%$ and $95 \%$ identities with the horse isolated EHV-1 and EHV9 respectively. These results confirmed that zebra-borne EHV-1 is a subtype of EHV-1[5]. An acute and lethal infection of EHV-9, EHV-1 and Zebra borne EHV-1 via intranasal inoculation was performed in Syrian hamsters $[\mathbf{4}, \mathbf{6}]$. Clinical signs of infected hamsters include the loss of bodyweight, nasal and ocular discharges, and apparent neurological symptoms. Therefore, the hamster is the best model for studying the pathogenesis and 
neurovirulence of theses neurotropic herpes viruses. Cytokines are small glycoproteins produced by many cell types, especially leukocytes that regulate immunity, inflammation and hematopoiesis. They regulate some physiological and pathological functions including innate immunity, acquired immunity and a plethora of inflammatory responses[7]. The role of cytokines in the pathogenesis of EHV-1and other herpes viruses were previously reported [8-10], but their role in the pathogenesis of EHV-9 and Zebra borne EHV-1 was not previously reported. Therefore, the aim of the present study is to illustrate the clinical role of the three cytokines (TNF- $\alpha$, IFN- $y$ and IL-6) and compare their pattern in the pathogenesis of EHV-9, EHV-1 and Zebra borne EHV-1 after intranasal inoculation in hamster model.

\section{Virus culture preparation.}

\section{Materials And Methods}

MDBK cells were used for propagation of EHV-9, EHV-1 and Zebra borne EHV-1. The inocula were prepared by culturing the virus from original seed stocks of EHV-9, EHV-1 and Zebra borne EHV-1 (P20, 5th passage in MDBK cells) in MDBK cells respectively. The viruses were titrated by plaque forming assay on MDBK cells. The titer of virus suspension was $1 \times 10^{4}$ P.F.U $/ \mathrm{ml}$ (Laboratory of Veterinary Microbiology, Gifu University, Japan).

\section{Animals and experimental design.}

Eighty four specific pathogen-free male Syrian hamsters (Mesocricetus auratus), 4 weeks old, were used in the study. The hamsters were purchased from a breeder (SLC Inc., Hamamatsu, Japan). The animal groups were acclimatized for two days before inoculation with virus, and were housed in an isolated biohazard cabinet, fed a basal diet of pellets (Oriental MF, Oriental Yeast Co., Tokyo, Japan) and allowed sterilized water ad libitum.

Hamsters were randomly divided into four groups; each group includes twenty one animals (Table 1), with each group housed separately to prevent cross-infection. The first group served as control group; the second group received an inoculation of EHV-9; the third group received an inoculation of EHV-1 and the fourth group received an inoculation of Zebra borne EHV-1. The EHV-9, EHV-1 and Zebra borne EHV-1 infected groups were inoculated intranasally with $50 \mu \mathrm{l}$ with $1 \times 10^{4}$ plaque forming units (pfu) of EHV-9 or EHV-1 or Zebra borne EHV-1 in solution, divided onto both nostrils while the animals were under deep anesthesia. The control group was inoculated with MEM- $\alpha$ medium. Three hamsters from each group were sacrificed at $1^{\text {st }}, 2^{\text {nd }}, 3^{\text {rd }}, 4^{\text {th }}, 5^{\text {th }}, 6^{\text {th }}$ and $7^{\text {th }}$ DPI. This study was approved by the Committee of Gifu University Animal Experiments. All animal handling and procedures were performed in accordance with the appropriate institutional animal care guidelines.

Table 1: Experimental design for the groups of hamsters.

\begin{tabular}{|c|c|c|c|c|c|c|c|c|c|}
\hline \multirow[t]{2}{*}{ Inoculated virus } & \multirow[t]{2}{*}{ Dose/Route } & \multicolumn{8}{|c|}{ No. of animals euthanized on DPI } \\
\hline & & $1^{\text {st }}$ & $2^{\text {nd }}$ & $3^{\text {rd }}$ & $4^{\text {th }}$ & $5^{\text {th }}$ & $6^{\text {th }}$ & $7^{\text {th }}$ & Total \\
\hline Control & $\begin{array}{l}50 \mu 1 \text { MEM- }-\alpha \\
\text { Intranasal }\end{array}$ & 3 & 3 & 3 & 3 & 3 & 3 & 3 & 21 \\
\hline EHV-9 & $\begin{array}{l}50 \mu \mathrm{l}\left(1 \times 10^{4}\right. \\
\text { pfu }) \text { Intranasal }\end{array}$ & 3 & 3 & 3 & 3 & 9 & - & - & 21 \\
\hline EHV-1 & $\begin{array}{l}50 \mu \mathrm{l}\left(1 \times 10^{4}\right. \\
\text { pfu }) \text { Intranasal }\end{array}$ & 3 & 3 & 3 & 3 & 3 & 3 & 3 & 21 \\
\hline $\begin{array}{c}\text { Zebra borne } \\
\text { EHV-1 }\end{array}$ & $\begin{array}{l}50 \mu \mathrm{l}\left(1 \times 10^{4}\right. \\
\text { pfu }) \text { Intranasal }\end{array}$ & 3 & 3 & 3 & 3 & 3 & 3 & 3 & 21 \\
\hline
\end{tabular}

\section{Clinical evaluation.}

Hamsters were monitored three times daily for 7 DPI for any clinical signs and measured for their body weight gain.

\section{Collection and processing of blood samples.}

Three hamsters from each group were euthanized by intraperitoneal administration of pentobarbital sodium $(100 \mathrm{mg} / \mathrm{kg})$ on $1,2,3,4,5,6$ and 7 DPI.

Blood samples were collected directly from the heart of each hamster at different time points, kept in epindorf tube without anticoagulant for separation of serum for detection of inflammatory cytokines (TNF- $\alpha$, IFN- $y$ and IL-6). 
Clinical effect of three important cytokines on the pathogenesis of equine herpes virus 9 (EHV-9),

5.Enzyme-linked immunosorbent assay for the determination of cytokines levels in serum.

The level of TNF- $\alpha$, IFN- $\gamma$ and IL- 6 were determined in the serum samples of infected hamsters at different time points and compared with the control (non-infected) hamsters at the same time points to determine differences between EHV-9, EHV-1 and Zebra borne EHV-1 infected groups in the induction of cytokines. We used a hamster TNF- $\alpha$ superfamily, member 2 ELISA kit, hamster IFN- $\gamma$ ELISA kit (My Biosource Company, San Diego, California, USA) and hamster IL- 6 ElIZA kits (CUSABIO). Each sample was tested in duplicate with a standard to obtain accurate results. The absorbance was measured by an iMark Microplate Absorbance Reader (Bio-Rad) using a dual wavelength measurement mode with a $450 \mathrm{~nm}$ filter and a $630 \mathrm{~nm}$ reference filter for TNF- $\alpha$ and using a single wave length for IFN- $\gamma$ and IL- 6 at $450 \mathrm{~nm}$ as recommended according to the kit inserts. An unknown concentration of the samples was obtained from the analysis of the standard curve on Microsoft Excel software 2010 using the following formula =IFERROR(TREND(A2:A8,B2:B8,B23),"').

\section{Statistical analysis.}

One-way analysis of variance was followed by Tukey Kramer's test via Graph Pad Prism version 5 was used for statistical analysis of changes in bodyweight gain and levels of serum cytokines (TNF- $\alpha$, INF- $y$, and IL-6). Comparisons were considered significant at $\mathrm{P}$ value $\leq 0.05$.

\section{III.}

\section{Results}

\section{Clinical Findings.}

Clinical signs in EHV-9, EHV-1 and Zebra borne EHV-1 were in the form of nervous and respiratory signs (depression, inappetance, nasal discharge, bilateral nasal hemorrhage, salivation, lack of coordination and periodic convulsions).

EHV-9 infected group showed clinical signs at $3^{\text {rd }}$ DPI in about fourteen animals then clinical signs include all the animals at $4^{\text {th }}$ DPI. Clinical signs were more severe than both EHV-1 and Zebra borne EHV-1 infected groups as they developed to lateral recumbancy and coma then death of six animals; one at $4^{\text {th }}$ DPI at $2^{\text {nd }} 12 \mathrm{~h}$ and five animals at $5^{\text {th }}$ DPI. While EHV-1infected group showed clinical signs at $4^{\text {th }}$ DPI in eleven animals from twelve then include all animals at $2^{\text {nd }} 12 \mathrm{~h}$ of the same day. However, Zebra borne EHV-1infected group showed clinical signs at $4^{\text {th }}$ DPI in three animals from nine at $2^{\text {nd }} 12 \mathrm{hr}$ then increased to seven from nine at $5^{\text {th }}$ DPI then include all the animals at the rest of days post infection. The number of affected animals out of live animals at each day of the experiment (table 2).

Table 2: The number of affected animals out of live animals at each day of the experiment.

\begin{tabular}{|c|c|c|c|c|c|c|c|c|c|c|c|c|c|c|c|}
\hline \multirow{3}{*}{ Groups } & \multicolumn{15}{|c|}{ DPI } \\
\hline & \multicolumn{2}{|c|}{ 0day } & \multicolumn{2}{|c|}{$1^{\text {t5 DPI }}$} & \multicolumn{2}{|c|}{$2^{\text {nd }}$ DPI } & \multicolumn{2}{|c|}{$3^{\text {rd }}$ DPI } & \multicolumn{2}{|c|}{$4^{4}$ DPI } & \multicolumn{2}{|c|}{$5^{4}$ DPI } & \multicolumn{2}{|c|}{$6^{\mathrm{k}} \mathrm{DPI}$} & $\overline{7^{2} \mathrm{DPI}}$ \\
\hline & $\begin{array}{l}1 \text { st } \\
12 \mathrm{~h}\end{array}$ & $\begin{array}{l}\text { 2nd } \\
12 \mathrm{~h}\end{array}$ & $\begin{array}{l}\text { lst } \\
12 \mathrm{~h}\end{array}$ & $\begin{array}{l}\text { 2nd } \\
12 \mathrm{~h}\end{array}$ & $\begin{array}{l}1 \text { st } \\
12 \mathrm{~h}\end{array}$ & $\begin{array}{l}\text { 2nd } \\
12 \mathrm{~h}\end{array}$ & $\begin{array}{l}\text { lst } \\
12 \mathrm{~h}\end{array}$ & $\begin{array}{l}2^{\text {nd }} \\
12 \mathrm{~h}\end{array}$ & $\begin{array}{l}1^{\text {th }} \\
12 \mathrm{~h}\end{array}$ & $\begin{array}{l}2^{\text {nd }} \\
12 \mathrm{~h}\end{array}$ & $\begin{array}{l}1^{\text {th }} \\
12 \mathrm{~h}\end{array}$ & $\begin{array}{l}2^{\text {nd }} \\
12 \mathrm{~h}\end{array}$ & $\begin{array}{c}1^{1 t} \\
12 \mathrm{~h}\end{array}$ & $\begin{array}{l}2^{\text {nd }} \\
12 \mathrm{~h}\end{array}$ & $\begin{array}{cl}1^{\text {th }} & 2^{\text {nd }} \\
12 \mathrm{~h} & 12 \mathrm{~h}\end{array}$ \\
\hline Control group & $0 / 21$ & $0 / 21$ & $0 / 21$ & $0 / 18$ & $0 / 18$ & $0 / 15$ & $0 / 15$ & $0 / 12$ & $0 / 12$ & $0 / 9$ & $0 / 9$ & $0 / 6$ & $0 / 6$ & $0 / 3$ & $0 / 3$ \\
\hline $\begin{array}{c}\text { EHV-9 } \\
\text { (Infected group) }\end{array}$ & $0 / 21$ & $0 / 21$ & $0 / 21$ & $0 / 18$ & $0 / 18$ & $0 / 15$ & $14 / 15$ & $11 / 12$ & $12 / 12$ & $\begin{array}{c}* \\
8 / 9\end{array}$ & $\begin{array}{l}3 \text { life } \\
\text { 5dead* }\end{array}$ & & & & \\
\hline $\begin{array}{c}\text { EHV-1 } \\
\text { (Infected group) }\end{array}$ & $0 / 21$ & $0 / 21$ & $0 / 21$ & $0 / 18$ & $0 / 18$ & $0 / 15$ & $0 / 15$ & $0 / 12$ & $11 / 12$ & 9/9 & $9 / 9$ & $6 / 6$ & $6 / 6$ & $3 / 3$ & $3 / 3$ \\
\hline $\begin{array}{c}\text { Zebra born EHV- } \\
1 \\
\text { (Infected group) }\end{array}$ & $0 / 21$ & $0 / 21$ & $0 / 21$ & $0 / 18$ & $0 / 18$ & $0 / 15$ & $0 / 15$ & $0 / 12$ & $0 / 12$ & $3 / 9$ & $7 / 9$ & $6 / 6$ & $6 / 6$ & $3 / 3$ & $3 / \mathbf{3}$ \\
\hline
\end{tabular}

* means number of deaths 


\section{Change in the body weight gain.}

EHV-9, EHV-1 and Zebra borne EHV-1infected groups showed significant reduction $(\mathrm{P} \leq 0.05)$ in body weight gain respectively compared to control group. EHV-9 infected group showed significant reduction ( $\mathrm{P} \leq$ 0.05 ) in body weight gain compared to both EHV-1 and Zebra borne EHV-1infected groups respectively and EHV-1infected group showed significant reduction $(\mathrm{P} \leq 0.05)$ in body weight gain compared to Zebra borne EHV-1infected group (fig. 1, 2)

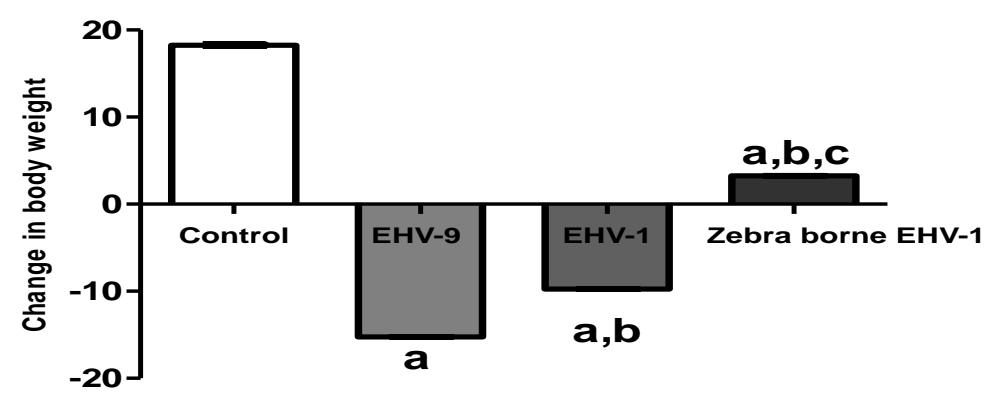

Figure 1 : Change in body weights of hamsters infected with EHV-9, EHV-1 and Zebra borne EHV-1 after 7 days of infection.

a: Significant from control. b: Significant from EHV-9. C: Significant from EHV-1

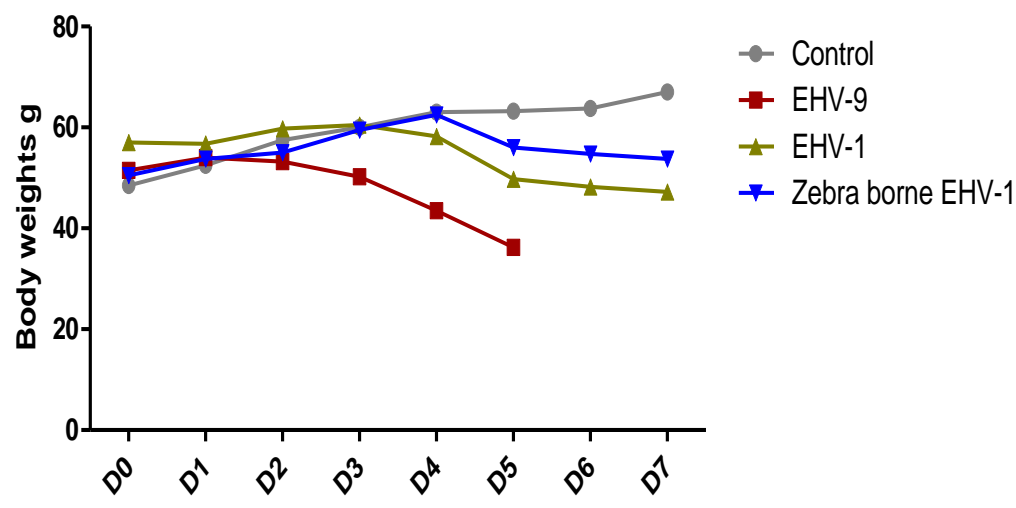

Figure 2 : Effect of EHV-9, EHV-1 and Zebra borne EHV-1 on body weight of hamsters over 7 DPI.

\section{Enzyme-linked immunosorbent assay for detection of cytokines level in serum.}

a. Enzyme-linked immunosorbent assay for detection of TNF- $\alpha$ level in serum.

Serum TNF- $\alpha$ level in EHV-9, EHV-1 and Zebra borne EHV-linfected group was significantly increased $(\mathrm{P} \leq 0.05)$ starting from $3^{\text {rd }}$ DPI until the end of experiment compared to the control group. There was a significant increase $(\mathrm{P} \leq 0.05)$ in serum TNF- $\alpha$ level in EHV-9 infected group compared to both EHV-1 and Zebra borne EHV-1 infected group at both $3^{\text {rd }}$ and $5^{\text {th }}$ DPI. Both EHV-1 and Zebra borne EHV-1 infected groups showed decrease in serum TNF- $\alpha$ level at $6^{\text {th }}$ and $7^{\text {th }}$ DPI compared to $5^{\text {th }}$ DPI (fig. 3A, B).

A

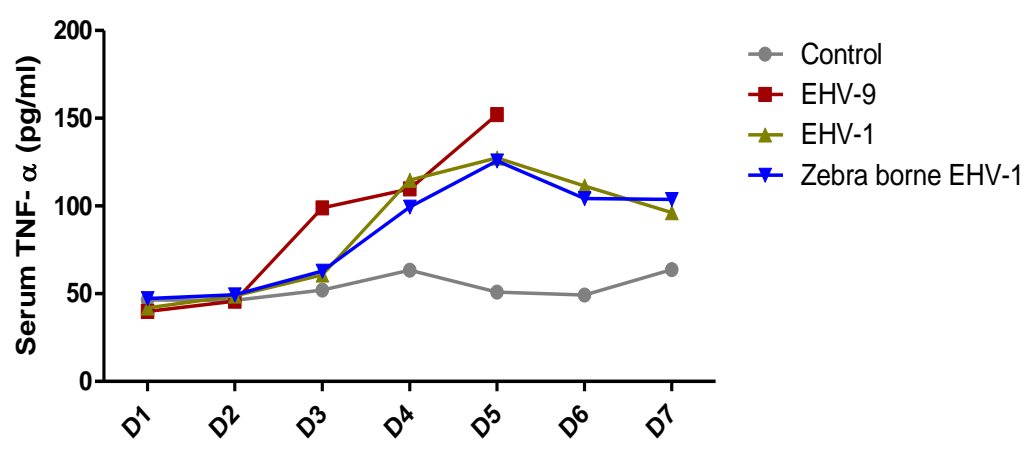


B
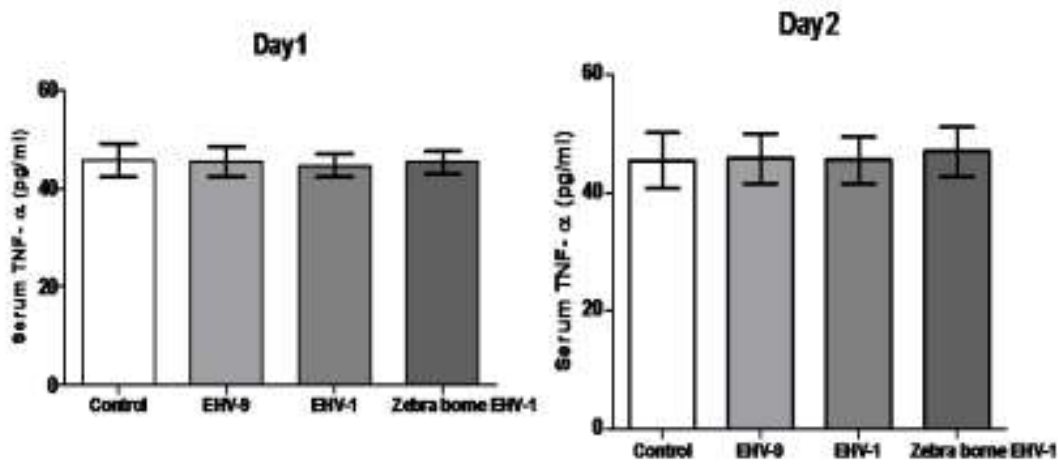

Day3

Day4
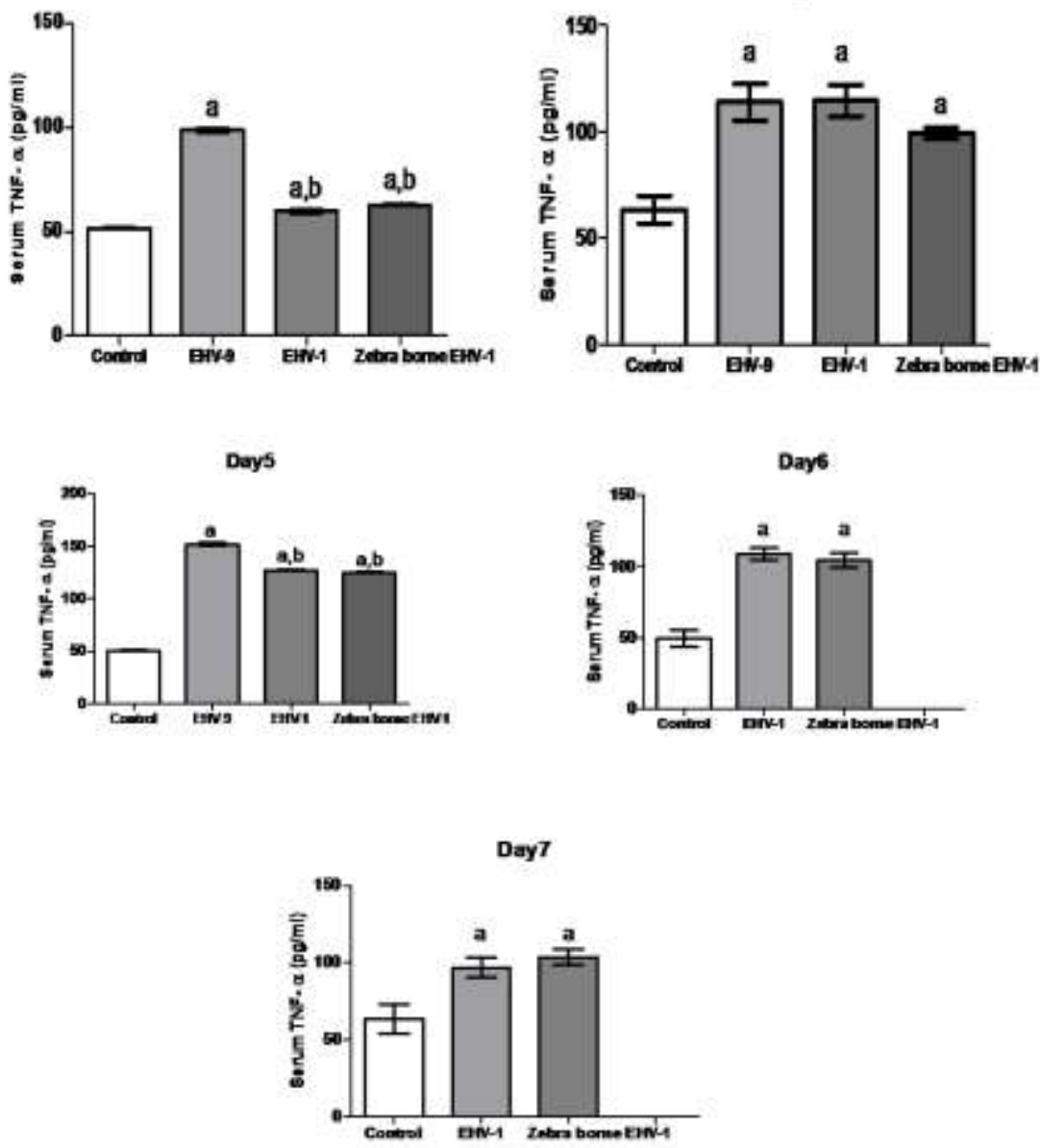

Figure 3 (A, B): Serum TNF-a level in hamsters infected with EHV-9, EHV-1 and Zebra borne EHV1respectively over 7 DPI. a: Significant from control, b: Significant from EHV-9,c: Significant from EHV-1, P $\leq 0.05$

b. Enzyme-linked immunosorbent assay for detection of IFN-y level in serum.

Serum IFN-y level in EHV-9, EHV-1 and Zebra borne EHV-1infected group was significantly increased starting from the $2^{\text {nd }}$ DPI to the $5^{\text {th }}$ DPI compared to the control group. EHV -9 infected group showed a significant increase $(\mathrm{P} \leq 0.05)$ in serum IFN-y level compared to both EHV-1 and Zebra borne EHV-1infected group at $3^{\text {rd }}$ and $4^{\text {th }}$ DPI. However, Zebra borne EHV-1infected group showed a significant decrease $(\mathrm{P} \leq 0.05)$ in serum IFN-y level compared to both EHV-9 and EHV-1 infected group at $4^{\text {th }}$ and $5^{\text {th }}$ DPI. Both EHV-1 and Zebra borne EHV-1infected group showed no significant change $(\mathrm{P} \leq 0.05)$ in serum IFN-y level compared to the control group at $6^{\text {th }}$ and $7^{\text {th }}$ DPI, serum IFN- $y$ level decreased and became nearly similar to its level in the control group (fig. 4 A, B). 
$\mathbf{A}$

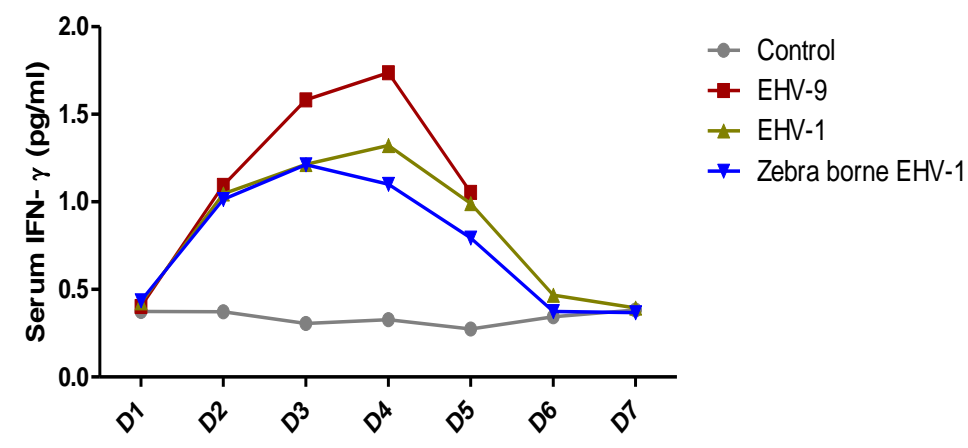

B
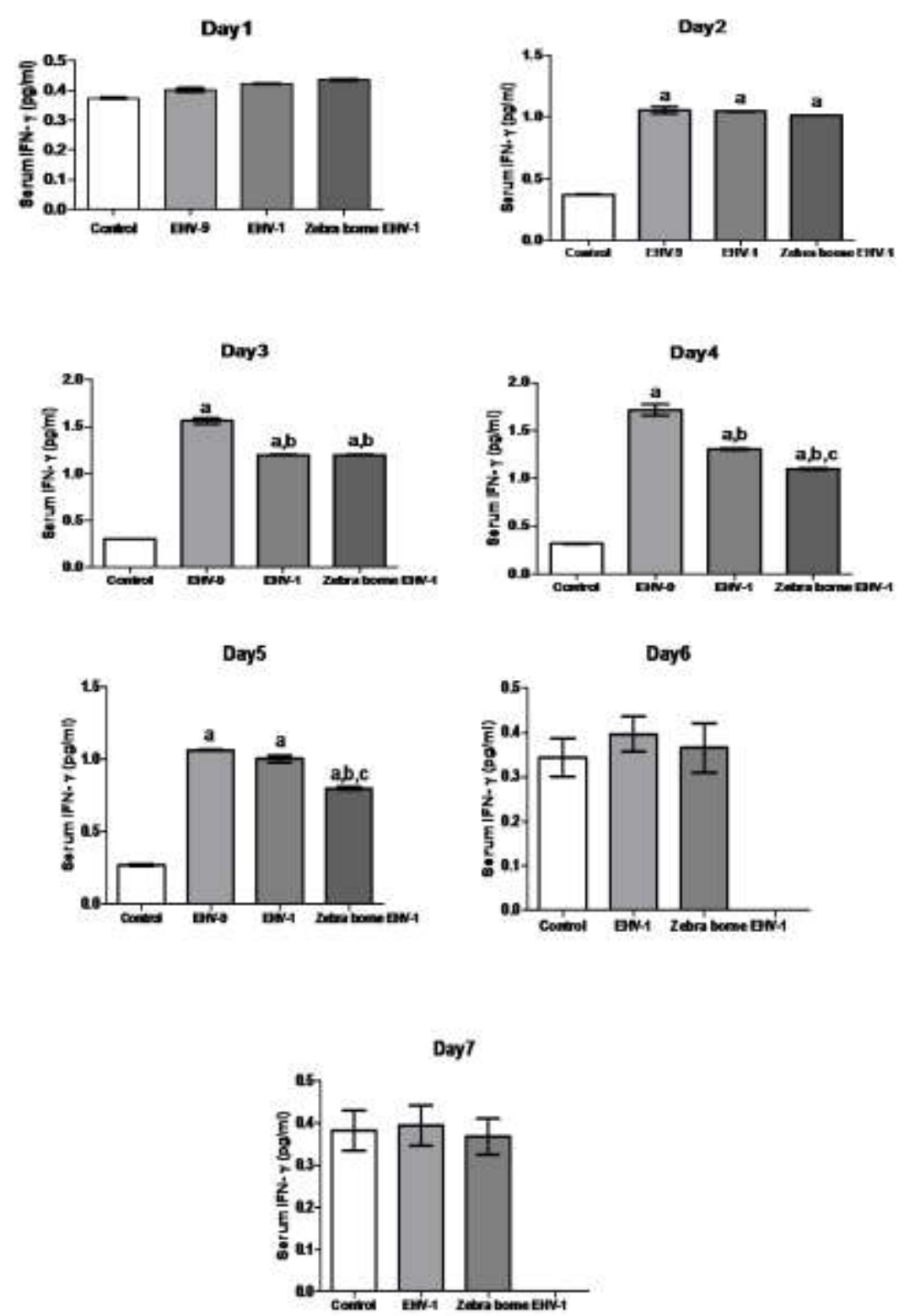

Figure 4 (A, B): Serum IFN-y level in hamsters infected with EHV-9, EHV-1 and Zebra borne EHV1respectively over 7 DPI. a: Significant from control, b: Significant from EHV-9,c: Significant from EHV-1, P $\leq$ 0.05 
c. Enzyme-linked immunosorbent assay for detection of IL-6 level in serum.

Serum IL-6 level in EHV-9, EHV-1 and Zebra borne EHV-1infected group was significantly increased $(\mathrm{P} \leq 0.05)$ starting from the $3^{\text {rd }}$ DPI until the end of the experiment compared to the control group. EHV-9 infected group showed significant increase $(\mathrm{P} \leq 0.05)$ in serum IL-6 compared to both EHV-1 and Zebra borne EHV-1 at $4^{\text {th }}$ DPI, but EHV-9 infected group showed significant increase $(P \leq 0.05)$ in serum IL-6 compared to Zebra borne EHV-1 at $5^{\text {th }}$ DPI(fig. 5 A,B).

A

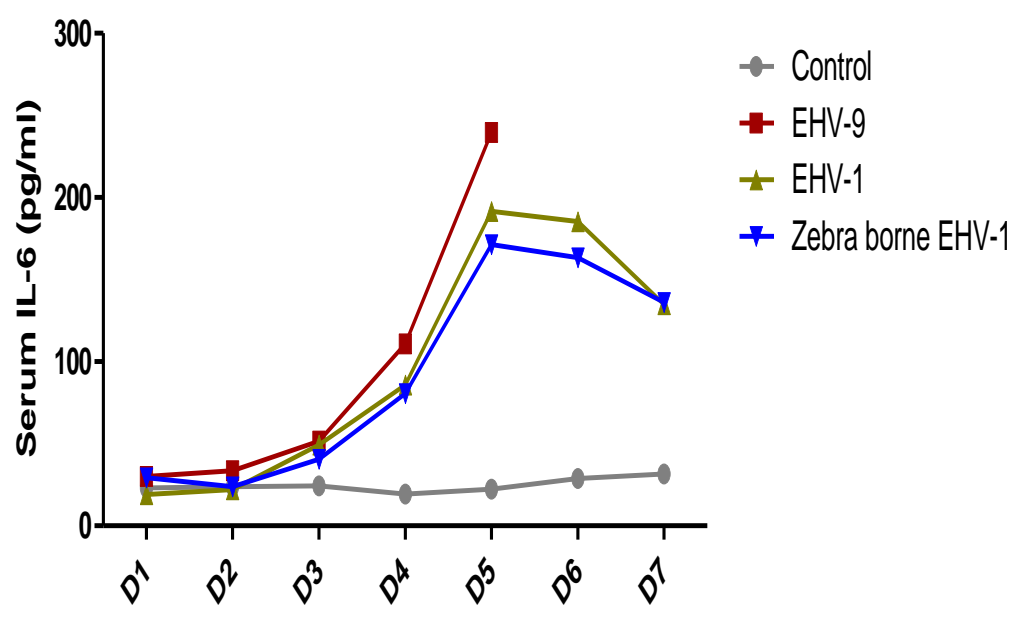

B
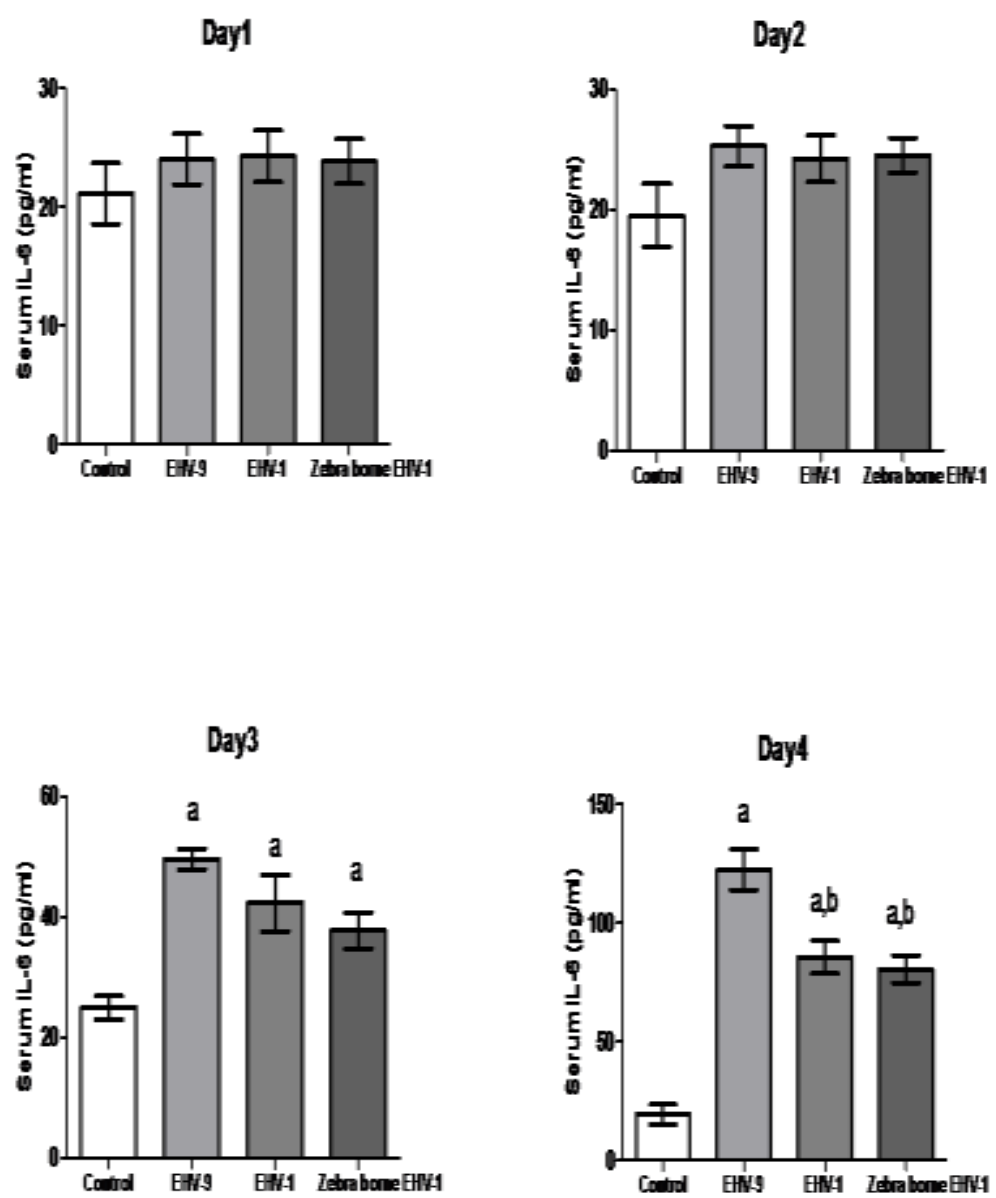

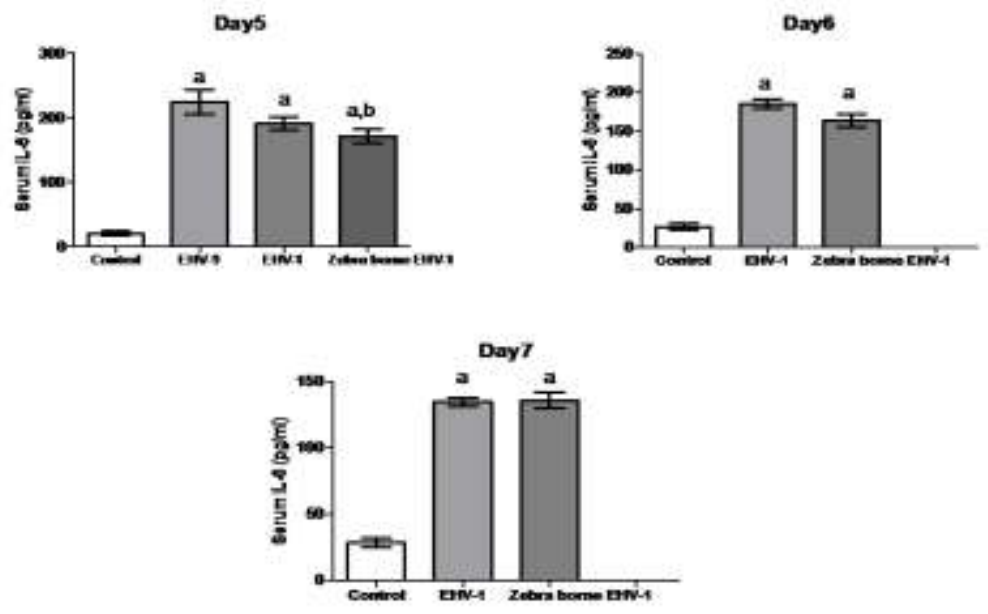

Figure 5 (A, B): Serum IL-6 level in hamsters infected with EHV-9, EHV-1 and Zebra borne EHV1respectively over 7 DPI. a: Significant from control, b: Significant from EHV-9,c: Significant from EHV-1, P $\leq$ 0.05 .

\section{Discussion}

Clinically, EHV-9 infected group showed the clinical signs earlier $\left(3^{\text {rd }} \mathrm{DPI}\right)$ than both EHV-1 and Zebra borne EHV-1 infected groups $\left(1^{\text {st }} 12 \mathrm{~h}\right.$ and $2^{\text {nd }} 12 \mathrm{~h}$ at $4^{\text {th }}$ DPI respectively). Clinical signs were more severe and progressive in EHV-9 infected group than other two infected groups. Mortalities were observed in EHV-9 infected group and not observed in both other two infected groups as showed in table 2. Although previous studies reported that Zebra borne EHV-1 is more virulent clinically than EHV-1 in experimental infection of hamsters [6], our results confirm that EHV-1 is slightly more virulent clinically than Zebra borne EHV-1 and EHV-9 is highly virulent clinically than both EHV-1 and Zebra borne EHV-1. This the first report comparing the virulence of those three important herpes viruses.

EHV-9 infected group showed significant reduction $(\mathrm{P} \leq 0.05)$ in body weight gain compared to both EHV-1 and Zebra borne EHV-1infected groups respectively and EHV-1infected group showed significant reduction $(\mathrm{P} \leq 0.05)$ in body weight gain compared to Zebra borne EHV-linfected group (fig. 1, 2). The decrease in body weight gain due to EHV-9 infection is in accordance to those obtained by [4, 11-13]. Both EHV-1 and Zebra borne EHV-1infected groups showed weight loss at $5^{\text {th }}$ DPI reaching maximum weight loss at $7^{\text {th }}$ DPI. These results were in accordance with $[6,14]$. Therefore, we suggest that, the decrease in body weight gain was mainly due to in appetence and dehydration, which resulted from severe tremors, convulsions, and recumbency. This was confirmed by observations of an empty stomach and distended gall bladder during the necropsy.

Cytokine-mediated immunity plays an important role in the pathogenesis of many diseases including infectious and autoimmune diseases[15]. Cytokines profile evaluation and their role in the pathogenesis of herpes viruses is previously reported in EHV-1 neuropathogenesis $[10,16]$, but not previously reported in EHV9 and Zebra borne EHV-1 pathogenesis, So in this experiment we investigate and compare the role of TNF- $\alpha$, IFN-y and IL-6 in the pathogenesis of EHV-1, EHV-9 and Zebra borne EHV-1.

Our results revealed that, Serum TNF- $\alpha$ level in EHV-9, EHV-1 and Zebra borne EHV-1infected group was significantly increased $(\mathrm{P} \leq 0.05)$ starting from $3^{\text {rd }}$ DPI until the end of experiment compared to the control group. There was a significant increase $(\mathrm{P} \leq 0.05)$ in serum TNF- $\alpha$ level in EHV-9 infected group compared to both EHV-1 and Zebra borne EHV-1 infected group at both $3^{\text {rd }}$ and $5^{\text {th }}$ DPI. In EHV-9 infected group, necropsy was ended by the $5^{\text {th }}$ DPI as the animals did not survive until $6^{\text {th }}$ DPI, so no blood samples collected after $5^{\text {th }}$ DPI. Both EHV-1 and Zebra borne EHV-1 infected animals survive until the end of experiment as they showed decrease in serum TNF- $\alpha$ level at $6^{\text {th }}$ and $7^{\text {th }}$ DPI compared to $5^{\text {th }}$ DPI (fig. 3A, B). The significant increase in TNF- $\alpha$ in the three groups of infected animals may be responsible for the signs of encephalitis and the decreased body weight gain as TNF- $\alpha$ act as an endogenous pyrogen on cells in hypothalamic regulatory regions of the brain inducing inflammation (heat, swelling, redness), fever and suppresses appetite [7]. The significant increase in TNF- $\alpha$ in EHV-9 infected group compared to both other two infected groups may explain the severe and progressive clinical signs compared to the other two infected groups.

In addition to, serum IFN-y level in EHV-9, EHV-1 and Zebra borne EHV-1infected group was significantly increased starting from the $2^{\text {nd }}$ DPI to the $5^{\text {th }}$ DPI compared to the control group. EHV-9 infected group showed a significant increase $(\mathrm{P} \leq 0.05)$ in serum IFN-y level compared to both EHV-1 and Zebra borne 
EHV-1infected group at $3^{\text {rd }}$ and $4^{\text {th }}$ DPI. However, Zebra borne EHV-1infected group showed a significant decrease $(\mathrm{P} \leq 0.05)$ in serum IFN-y level compared to both EHV-9 and EHV-1 infected group at $4^{\text {th }}$ and $5^{\text {th }}$ DPI. Both EHV-1 and Zebra borne EHV-1infected group showed no significant change $(\mathrm{P} \leq 0.05)$ in serum IFN-y level compared to the control group at $6^{\text {th }}$ and $7^{\text {th }}$ DPI, serum IFN-y level decreased and became nearly similar to its level in the control group (fig.4 A,B). IFN- $\gamma$ modulates a number of components of the immune response. IFN- $\gamma$ is produced by activated T lymphocytes (TH1 and CD8+ cells), NK cells, B cells and NKT cells. It promotes the activity of cytolytic T lymphocytes, macrophages and NK cells. The early host defense against infection is likely to utilize IFN- $\gamma$ secreted by NK and professional APCs. In acquired immune responses, T lymphocytes are the major source of IFN- $\gamma$ [7]. IFN- $\gamma$ induction is increased after EHV-1 infection especially in non vaccinated ponies as protective immunity to infection [16], this report is in accordance to our results for the three groups of infected animals. IFN- $\gamma$ augments TNF- $\alpha$ synthesis and both mediate many aspects of the disease, both TNF- $\alpha$ and IFN- $\gamma$ are directly toxic to oligodendrocytes and can stimulate others local inflammatory cytokine production [17-19].

The decreased level of TNF- $\alpha$ and non significant change in serum IFN-y level in both EHV-1 and Zebra borne EHV-1infected group compared to the control group at $6^{\text {th }}$ and $7^{\text {th }}$ DPI may indicate low propagation of virus and possibility of virus clearance. This is in accordance with $[\mathbf{2 0 , 2 1 ]}$ as they reported an increase in TNF- $\alpha$ and IFN-y in the first days following infection with EHV-1 in ponies coincide with onset of fever, viremia and the onset of respiratory manifestation followed by decreased level may reach baseline when fever subsides.

IL-6 is known to play an important role in initiating and maintaining inflammatory responses during infection as well as autoimmune diseases [22]. Serum IL-6 level in EHV-9, EHV-1 and Zebra borne EHVlinfected group was significantly increased $(\mathrm{P} \leq 0.05)$ starting from the $3^{\text {rd }}$ DPI until the end of the experiment compared to the control group. EHV-9 infected group showed significant increase $(\mathrm{P} \leq 0.05)$ in serum IL-6 compared to both EHV-1 and Zebra borne EHV-1 at $4^{\text {th }}$ DPI, but EHV-9 infected group showed significant increase $(\mathrm{P} \leq 0.05)$ in serum IL-6 compared to Zebra borne EHV-1 at $5^{\text {th }}$ DPI(fig. 5A,B $)$. IL-6 could have a role in the neuropathology, its expression increases following axonal damage, mainly in neurons and in the presence of IFN-y and TNF- $\alpha[7,8,23]$. This explain the synergestic effect between IFN- $y$, TNF- $\alpha$ and IL-6 in the pathogenesis of the three herpes viruses.

\section{Conclusion}

From the previous results, we can conclude that EHV-9 is more virulent clinically than both EHV-1 and Zebra borne EHV-1 and EHV-1 is slightly more virulent clinically than Zebra borne EHV-1. Cytokines (IFN- $y$, TNF- $\alpha$ and IL-6) have an important role in the pathogenesis of the three herpes viruses and EHV-9 is more virulent in induction of the three cytokines than both EHV-1 and Zebra borne EHV-1, Further studies are necessary to detect additional cytokines that contribute to the pathogenesis of EHV-9, EHV-1 and Zebra borne EHV-1.

\section{Acknowledgments}

This study was supported in part by a grant-in-aid (emerging-general) for scientific research from the Ministry of Health, Labor, and Welfare of Japan; a grant from Hokkaido University; and a grant from Ono Pharmaceutical Co, Ltd. Our gratitude to the staff members of the Pathology and Microbiology Department at the Faculty of Applied Biological Science, Gifu University, and the Animal Medicine Department, Faculty of Veterinary Medicine, Damanhour University, who contributed to this work.

\section{References}

[1]. J. Patel and J. Heldens, Equine herpesviruses 1 (EHV-1) and 4 (EHV-4)-epidemiology, disease and immunoprophylaxis: a brief review, The Veterinary Journal, 170(1), 2005, 14-23.

[2]. H. FUKUSHI, T. TOMITA, A. TANIGUCHI, Y. OCHIAI, R. KIRISAWA, T. MATSUMURA, T. YANAI, T. MASEGI, T. YAMAGUCHI, and K. HIRAI, Gazelle herpesvirus 1: a new neurotropic herpesvirus immunologically related to equine herpesvirus 1, Virology, 227(1), 1997, 34-44.

[3]. T. Yanai, T. Sakai, H. Fukushi, K. Hirai, M. Narita, H. Sakai, and T. Masegi, Neuropathological study of gazelle herpesvirus 1 (equine herpesvirus 9) infection in Thomson's gazelles (Gazella thomsoni). Journal of comparative pathology, 119(2), 1998, 159168.

[4]. H. Fukushi, A. Taniguchi, K. Yasuda, T. Yanai, T. Masegi, T. Yamaguchi, and K. Hirai, A hamster model of equine herpesvirus 9 induced encephalitis, Journal of neurovirology, 6(4), 2000, 314-319.

[5]. G. Xiaoqin, S. Izume, A. Okada, T. KIMURA, and H. FUKUSHI, Full genome sequences of zebra-borne equine herpesvirus type 1 isolated from zebra, onager and Thomson's gazelle, Journal of Veterinary Medical Science, 76(9), 2014, 1309-1312.

[6]. E. Ibrahim, M. Kinoh, T. Matsumura, M. Kennedy, G. Allen, T. Yamaguchi, and H. Fukushi, Genetic relatedness and pathogenicity of equine herpesvirus 1 isolated from onager, zebra and gazelle, Archives of Virology, 152(2), 2007, 245-255.

[7]. M.M. Khan, Role of Cytokines, in Immunopharmacology, Springer,2008, 33-59.

[8]. S.R. Paludan, Requirements for the induction of interleukin-6 by herpes simplex virus-infected leukocytes, Journal of virology, 75(17), 2001, 8008-8015. 
[9]. R. Paillot, J. Daly, V. Juillard, J. Minke, D. Hannant, and J. Kydd, Equine interferon gamma synthesis in lymphocytes after in vivo infection and in vitro stimulation with EHV-1, Vaccine, 23(36), 2005, 4541-4551.

[10]. G.S. Hussey, L.V. Ashton, A.M. Quintana, D.P. Lunn, L.S. Goehring, K. Annis, and G. Landolt, Innate immune responses of airway epithelial cells to infection with Equine herpesvirus-1, Veterinary Microbiology, 170(1), 2014, 28-38.

[11]. T. Yanai, S. Tujioka, H. Sakai, H. Fukushi, K. Hirai, and T. Masegi, Experimental infection with equine herpesvirus 9 (EHV-9) in cats, Journal of comparative pathology, 128(2), 2003, 113-118.

[12]. T. Yanai, N. Fujishima, H. Fukushi, A. Hirata, H. Sakai, and T. Masegi, Experimental infection of equine herpesvirus 9 in dogs, Veterinary Pathology, 40 (3),2003, 263-267.

[13]. E. El-Nahass, N. El-Habashi, M. Nayel, S. Kasem, H. Fukushi, Y. Suzuki, A. Hirata, H. Sakai, and T. Yanai, Kinetics and pathogenicity of equine herpesvirus-9 infection following intraperitoneal inoculation in Hamsters, Journal of comparative pathology, 145(2), 2011, 271-281.

[14]. S. Kasem, M.H.H. Yu, S. Yamada, A. Kodaira, T. Matsumura, K. Tsujimura, H. Madbouly, T. Yamaguchi, K. Ohya, and H. Fukushi, The ORF37 (UL24) is a neuropathogenicity determinant of equine herpesvirus 1 (EHV-1) in the mouse encephalitis model, Virology, 400(2), 2010, 259-270.

[15]. H. Yoshida, M. Nakaya, and Y. Miyazaki, Interleukin 27: a double-edged sword for offense and defense. Journal of Leukocyte Biology, 86(6), 2009, 1295-1303.

[16]. D.K. Coombs, T. Patton, A.K. Kohler, G. Soboll, C. Breathnach, H.G. Townsend, and D. Lunn, Cytokine responses to EHV-1 infection in immune and non-immune ponies. Veterinary immunology and immunopathology, 111(1), 2006, 109-116.

[17]. E. Bettelli and L.B. Nicholson, The role of cytokines in experimental autoimmune encephalomyelitis, in Autoimmunity, Springer, 2001,109-127.

[18]. T. Vartanian, Y. Li, M. Zhao, and K. Stefansson, Interferon-gamma-induced oligodendrocyte cell death: implications for the pathogenesis of multiple sclerosis, Molecular Medicine, 1(7), 1995, 732.

[19]. J.S. Liu, T.D. Amaral, C.F. Brosnan, and S.C. Lee, IFNs are critical regulators of IL-1 receptor antagonist and IL-1 expression in human microglia, The Journal of Immunology, 161(4), 1998, 1989-1996.

[20]. C. Breathnach, G. Soboll, M. Suresh, and D. Lunn, Equine herpesvirus-1 infection induces IFN- $\gamma$ production by equine T lymphocyte subsets, Veterinary Immunology and Immunopathology, 103(3), 2005, 207-215.

[21]. G.S. Hussey, S.B. Hussey, B. Wagner, D.W. Horohov, G.R. Van de Walle, N. Osterrieder, L.S. Goehring, S. Rao, and D.P. Lunn, Evaluation of immune responses following infection of ponies with an EHV-1 ORF1/2 deletion mutant, Veterinary Research, 42(1), 2011, 23.

[22]. K. Ishihara and T. Hirano, IL-6 in autoimmune disease and chronic inflammatory proliferative disease, Cytokine \& growth factor reviews, 13(4), 2002, 357-368.

[23]. M. Erta, A. Quintana, and J. Hidalgo, Interleukin-6, a major cytokine in the central nervous system, International Journal of Biolological Science, 8(9), 2012, 1254-1266. 